\title{
QUALIDADE DE VIDA EM GESTANTES EM TEMPOS DE PANDEMIA DO COVID-
} 19

\section{QUALITY OF LIFE IN PREGNANT WOMEN IN COVID-19 PANDEMIC TIMES}

\author{
Isabella Mota Santos Abreu ${ }^{1}$ \\ Deborah Vendrami Beraldo Rosa² \\ Ana Vitória de Almeida Drubi ${ }^{3}$ \\ Beatriz Agustini ${ }^{4}$ \\ Marcia Nacif ${ }^{5}$
}

Resumo: O novo coronavírus (SARS-COV2), ganhou espaço em âmbito mundial de forma rápida e letal, sendo que os grupos com comorbidades são mais vulneráveis às formas críticas do vírus, pelo fato do risco elevado de morbimortalidade. Para prevenir maiores agravamentos, o Ministério da Saúde classificou as gestantes e puérperas, nas duas semanas após o parto, em grupo de risco da COVID-19. Este trabalho teve como objetivo avaliar a qualidade de vida de gestantes durante a pandemia do Coronavírus (Covid-19). Trata-se de um estudo transversal, realizado com a participação de gestantes durante o período de pandemia do COVID-19. A coleta de dados foi realizada através da aplicação de um questionário on-line na plataforma Google Forms, composto por questões para caracterização das gestantes (idade, idade gestacional, gestação única ou múltipla, alteração da alimentação durante o período gestacional, prática de atividade física e uso de suplementos alimentares) e qualidade de vida (WHOQOL-bref). Foram avaliadas 30 gestantes com idade média de 28 anos $( \pm 5,72)$ e idade gestacional média de 27 semanas. Em relação à alimentação, $73,3 \% \quad(n=22)$ das mulheres relataram terem melhorado sua dieta durante o período gestacional e $50 \%$ disseram fazer atividades físicas. Verificou-se que a maior parte das gestantes $(93,3 \%)$ apresentou uma qualidade de vida muito satisfatória. No entanto, sugere-se que novos estudos com amostras maiores, sejam realizados para garantir uma gestação saudável a todas as mulheres durante a pandemia do COVID-19.

Palavras-chave: Qualidade de Vida. Gestante. COVID-19.

Abstract: The new coronavirus (SARS-COV2), gained space worldwide quickly and lethally, and comorbid groups are more vulnerable to critical forms of the virus, due to the high risk of morbidity and mortality. To prevent further worsening, the Ministry of Health classified pregnant women and puerperal women in the COVID-19 risk group in the two weeks after delivery. This study aimed to assess the quality of life of pregnant women during a Coronavirus (Covid-19) pandemic. This is a cross-sectional study, carried out with the participation of pregnant women during the pandemic period of COVID-19. Data collection was carried out by applying an online questionnaire on the Google Forms platform, consisting of questions for the characterization of pregnant women (age, gestational age, single or multiple pregnancies, changes in diet during pregnancy, physical activity and use of dietary supplements) and quality of life

\footnotetext{
1 Universidade Presbiteriana Mackenzie, E-mail: isabella.m.santos@hotmail.com.

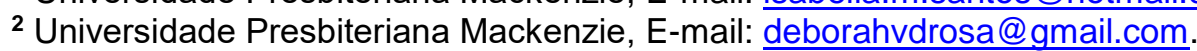

3 Universidade Presbiteriana Mackenzie, E-mail: avadrubi@hotmail.com.

${ }^{4}$ Universidade Presbiteriana Mackenzie, E-mail: agustinibe7@gmail.com.

${ }^{5}$ Universidade Presbiteriana Mackenzie, E-mail: marcia.nacif@mackenzie.br.
} 
(WHOQOL-bref). Thirty pregnant women with an average age of 28 years $( \pm 5.72)$ and an average gestational age of 27 weeks were evaluated. Regarding food, $73.3 \%$ $(n=22)$ of the women reported having improved their diet during pregnancy and $50 \%$ said they did physical activities. It was found that most pregnant women (93.3\%) had a very satisfactory quality of life. However, it is necessary that new studies with adults are carried out to guarantee a healthy pregnancy for all women during the COVID-19 pandemic.

Key words: Quality of Life. Pregnant. COVID-19.

Data de submissão: 23.12 .2020

Data de aprovação: 10.06.2021

Identificação e disponibilidade:

(https://revista.univap.br/index.php/revistaunivap/article/view/2572,

http://dx.doi.org/10.18066/revistaunivap.v27i55.2572).

\section{INTRODUÇÃO}

Em Wuhan, capital da província de Hubei na China, no final do ano de 2019, foi identificado um novo vírus, nomeado pela Organização Mundial da Saúde (OMS) como COVID-19/SARS-CoV-2 (WEFFORT et al., 2020).

Este vírus, é causador de uma doença com sintomas que começam gradualmente, os quais variam desde um simples resfriado, febre, dor de cabeça e tosse seca a condições mais agravantes e fatais. Além disso, alguns indivíduos que são infectados podem não apresentar sintomas (BRASIL, 2020a; BENVENUTO et al., 2020).

São considerados grupo de risco para agravamento da COVID-19 os portadores de doenças crônicas, como diabetes e hipertensão, asma, doença pulmonar obstrutiva crônica, e indivíduos fumantes, acima de 60 anos, gestantes, puérperas e crianças menores de 5 anos (BRASIL, 2020b).

Múltiplos pesquisadores vêm investigando a possibilidade de haver transmissão do SARS-CoV-2 durante a gravidez, mas sem êxito de evidências até o momento. Ainda não se sabe se é possível uma transmissão vertical entre a mãe e o bebê, faltando dados suficientes para controle e prevenção de infecções neonatais (GUEDES et al., 2020).

A gestação é um período em que ocorrem diversas alterações fisiológicas e psicológicas na mulher. Muitas gestantes estranham as mudanças físicas e, especialmente, emocionais durante os noves meses de gravidez. Este período já é marcado como um momento de medo e angústia para algumas mulheres, seja ela primigesta ou multípara (COSTA et al., 2018), sendo acentuado em meio a pandemia do novo Coronavírus (LÉLIS et al., 2020).

Em razão às informações incertas da ciência com relação aos riscos de infecção do vírus em gestantes, é compreensível o receio que as mulheres apresentam (ESTRELA et al., 2020). Existe ainda o receio das possíveis complicações ao decorrer da gestação e no momento do parto, como a probabilidade de uma transmissão vertical do vírus, os sintomas da doença no recém-nascido (HOFFMANN et al., 2020), além da insegurança de uma antecipação do parto (SANTANA; ELITO JÚNIOR, 2020).

Além do contexto biológico, pode-se perceber que a pandemia também levou à 
grandes mudanças no cotidiano, refletindo um desafio à resiliência psicológica. Levando em consideração esse cenário, um dos aspectos importantes a se ressaltar é a qualidade de vida de gestantes que enfrentam o momento de pandemia. A definição de qualidade de vida proposta pela Organização Mundial da Saúde (OMS) envolve o bem-estar espiritual, físico, mental, psicológico e emocional dos indivíduos, além de suas redes de relacionamento, saúde, educação, habitação e saneamento básico (BVS, 2013).

Recomenda-se, portanto, que nos atentemos não apenas aos riscos biológicos, mas com a vulnerabilidade das gestantes, assim como puérperas e do recém-nascido durante a pandemia (WAGNER et al., 2020).

A contribuição do profissional capacitado em orientar e esclarecer informações científicas, contribui diretamente para a diminuição do medo e da ansiedade. Assim, possibilitando as gestantes vivenciarem o momento com mais tranquilidade e de forma segura e saudável no processo de nascimento de seu bebê (CRUZ; FRANÇA; GRUBER, 2011).

Diante do exposto, este trabalho visa avaliar a qualidade de vida de gestantes durante a pandemia do Coronavírus (Covid-19).

\section{METODOLOGIA}

Trata-se de um estudo transversal, realizado com a participação de gestantes durante o período de pandemia do COVID-19. As mulheres foram recrutadas para a participação na pesquisa por meio de divulgação nas redes sociais.

A coleta de dados foi realizada através da aplicação de um questionário on-line na plataforma Google Forms. Foi composto por questões para caracterização das gestantes (idade, idade gestacional, gestação única ou múltipla, alteração da alimentação durante o período gestacional, prática de atividade física e uso de suplementos alimentares) e qualidade de vida (WHOQOL-bref).

A qualidade de vida foi avaliada pela aplicação da versão abreviada do instrumento de avaliação de qualidade de vida da Organização Mundial da Saúde, abreviado por WHOQOL-bref (The WHOQOL Group, 1998). Este instrumento de avaliação da qualidade de vida possui vinte e seis perguntas que foram organizadas em quatro domínios conforme exposto no Quadro 1.

Quadro 1 - Domínios do WHOQOL-bref.

\begin{tabular}{|ll|l|}
\hline \multicolumn{2}{|c|}{ Domínio } & \multicolumn{1}{c|}{ Aspectos Relacionados } \\
\hline 1. & Físico/Saúde & À saúde, doenças, trabalho e hábitos \\
\hline 2. & Psicológico & À satisfação pessoal, motivação no trabalho e auto estima \\
\hline 3. & Pessoal & $\begin{array}{l}\text { À família, crenças pessoais e religiosas e à cultura e de que forma } \\
\text { influenciam o trabalho. }\end{array}$ \\
\hline 4. & Profissional & Organizacionais que podem influenciar a vida das mulheres. \\
\hline & Fonte: Adaptado de Reis Júnior (2008).
\end{tabular}

Para analisar os resultados das aplicações do WHOQOL-bref, utilizou-se uma escala de classificação, conforme retratado no Quadro 2. 
Quadro 2 - Classificação proposta para o WHOQOL-bref.

\begin{tabular}{|c|c|c|c|c|}
\hline $\begin{array}{c}\text { Muito } \\
\text { Insatisfatório }\end{array}$ & Insatisfatório & Neutro & Satisfatório & $\begin{array}{c}\text { Muito } \\
\text { Satisfatório }\end{array}$ \\
\hline 0 a 22,5 & 22,5 a 45 & 45 a 55 & 55 a 77,5 & 77,5 a 100 \\
\hline
\end{tabular}

Fonte: adaptado de Reis Júnior (2008).

Antes do preenchimento do questionário on-line, as gestantes assinalaram o ícone "sim" para a pergunta "Você aceita participar desta pesquisa?". As participantes que declararam não aceitar foram direcionadas ao final do formulário, não respondendo ao questionário. A participação na pesquisa foi voluntária e as gestantes foram esclarecidas que poderiam deixar a pesquisa a qualquer momento. A pesquisa foi aprovada pelo Comitê de Ética em Pesquisa da Universidade Presbiteriana Mackenzie sob número CAAE: 50307715.7.0000.0084.

\section{RESULTADOS E DISCUSSÕES}

A amostra foi composta por 30 gestantes, as quais apresentaram idade média de 28 anos $( \pm 5,72)$ e idade gestacional média de 27 semanas (Tabela 1$)$.

Tabela 1 - Idade gestacional das gestantes avaliadas.

\begin{tabular}{cc} 
Idade Gestacional & Resultado \\
\hline $1^{\circ}$ Trimestre & $5(16,6 \%)$ \\
$2^{\circ}$ Trimestre & $12(40 \%)$ \\
$3^{\circ}$ Trimestre & $13(43,3 \%)$
\end{tabular}

Fonte: Os autores (2020).

Ao serem avaliadas quanto ao tipo de gestação, apenas $3,3 \% \quad(n=1)$ das participantes do estudo relataram ter uma gestação gemelar, ou seja, uma gestação múltipla.

Em relação a alimentação, 73,3 \% $(n=22)$ das mulheres relataram terem alterado sua dieta durante o período gestacional. Dentre as alterações retratadas, a diminuição de açúcar, frituras e alimentos industrializados foram as mais citadas. O aumento no consumo de alimentos in natura, como frutas, verduras e legumes também foi relatado e sugere um conhecimento de que há uma associação entre alimentação balanceada e gestação saudável. Algumas gestantes também declararam que deixaram de consumir alimentos crus fora de sua residência. Oliveira (2019), em seu estudo com gestantes de alto risco no munícipio de Vitória de Santo Antão (PE), também observou que $72,3 \%$ das entrevistadas consumiam diariamente frutas, verduras, legumes e grãos. No entanto, $64 \%$ das gestantes afirmaram consumir alimentos considerados não saudáveis, como enlatados, frituras e carnes gordas.

Ao avaliar a prática de atividades físicas, observou-se que metade das gestantes praticavam exercícios durante o período gestacional. Mediante as orientações de isolamento social exigidas atualmente em diversos países, estimular as gestantes a manter uma rotina fisicamente ativa nesse período de combate a disseminação da doença torna-se uma medida preventiva à saúde.

No decorrer do período gestacional, uma das doenças com maior incidência são as tromboembólicas. Segundo o estudo de Tang et al. (2020), onde analisou-se pacientes diagnosticados com COVID-19 grave, observou-se que $71,4 \%$ dos pacientes que não sobreviveram à doença e $0,6 \%$ dos que sobreviveram 
manifestaram sinais de coagulação intravascular disseminada, também conhecida como CID, sugerindo a frequência deste quadro em casos grave de COVID-19. As consequências negativas na saúde da gestante durante este período podem ser reduzidas com a prática de algum exercício físico (ALMEIDA; PORTUGAL; ASSIS, 2020). O American College Sports of Medicine (2020) publicou um guia que sugere a manutenção de uma vida ativa em domicílio durante o período de isolamento na pandemia do COVID-19, reforçando a importância de tais hábitos para a saúde, como a redução dos sentimentos de estresse e ansiedade. Neste guia, é destacado a influência que ficar sentado na maior parte do dia pode causar em sua saúde, sendo comparado com uma atividade moderada que está diretamente relacionada com uma melhora na função imune do indivíduo.

Quanto ao uso de suplementos alimentares, $73,3 \% \quad(n=22)$ das mulheres consumiam algum produto, sendo o ácido fólico, sulfato ferroso, ômega-3, probióticos e vitamina D os mais citados. Miorando e Maciel (2019) em uma pesquisa de caráter descritivo-exploratória com 57 puérperas, verificaram que 87,7\% $(n=50)$ foram suplementadas com sulfato ferroso, $82,4 \%(n=47)$ com ácido fólico, $5 \%(n=3)$ com ômega-3 e apenas $1 \%(n=1)$ com vitamina $D$ durante o período gestacional.

Ao serem avaliadas em relação a qualidade de vida, verificou-se que a maioria $(93,3 \%)$ das gestantes foi classificada como apresentando uma qualidade de vida muito satisfatória, conforme expresso na Tabela 2.

Tabela 2 - Avaliação da qualidade de vida das gestantes.

\begin{tabular}{cc}
\hline Classificação & \\
\hline Pontuação Média do WHOQOL-bref & $91,93( \pm 9,68)$ \\
Satisfatória & $6,6 \%(n=2)$ \\
Muito Satisfatória & $93,3 \%(n=28)$
\end{tabular}

Fonte: Os autores (2020).

Gadelha et al. (2020), ao estudarem 276 gestantes de alto risco, por meio da aplicação da versão brasileira do The Mother-Generated Index (MGI) observaram que $85,9 \%(n=67)$ das mulheres relataram ter baixa disposição/condição física. Problemas com sono e com a parte financeira, foram retratadas por $69,9 \%(n=86)$ e $75,9 \%(n=44)$ das mulheres, respectivamente.

No presente estudo, $43,3 \%(n=13)$ das mulheres disseram ter dinheiro suficiente para satisfazer suas necessidades, $26,7 \%(n=8)$ relataram estar insatisfeitas com seu sono e $26,7 \%(n=8)$ das gestantes demonstraram estar satisfeitas com o seu desempenho (Tabela 3). 
Tabela 3 - Qualidade de Vida das Gestantes.

\begin{tabular}{|c|c|c|c|c|c|c|}
\hline Domínio & & $\begin{array}{c}\text { Muito } \\
\text { insatisfeito }\end{array}$ & Insatisfeito & $\begin{array}{c}\text { Nem } \\
\text { Insatisfeito } \\
\text { Nem } \\
\text { Satisfeito }\end{array}$ & Satisfeito & $\begin{array}{c}\text { Muito } \\
\text { Satisfeito }\end{array}$ \\
\hline \multirow[t]{9}{*}{ Físico } & $\begin{array}{c}\text { Como você } \\
\text { avaliaria sua } \\
\text { qualidade de vida? }\end{array}$ & $3,3 \%$ & - & $10 \%$ & $60 \%$ & $26,7 \%$ \\
\hline & $\begin{array}{l}\text { Quão satisfeita } \\
\text { você está com a } \\
\text { sua saúde? }\end{array}$ & $3,3 \%$ & - & $20 \%$ & $60 \%$ & $16,7 \%$ \\
\hline & $\begin{array}{c}\text { Em que medida } \\
\text { você acha que sua } \\
\text { dor (física) impede } \\
\text { você de fazer o que } \\
\text { você precisa? }\end{array}$ & $23,3 \%$ & $23,3 \%$ & $26,7 \%$ & $23,3 \%$ & $3,3 \%$ \\
\hline & $\begin{array}{c}\text { O quanto você } \\
\text { precisa de algum } \\
\text { tratamento médico } \\
\text { para levar sua vida } \\
\text { diária? }\end{array}$ & $36,7 \%$ & $30 \%$ & $20 \%$ & $10 \%$ & $3,3 \%$ \\
\hline & $\begin{array}{c}\text { Você tem energia } \\
\text { suficiente para seu } \\
\text { dia-a-dia? }\end{array}$ & $3,3 \%$ & $20 \%$ & $56,7 \%$ & $16,7 \%$ & $3,3 \%$ \\
\hline & $\begin{array}{l}\text { Quão bem você é } \\
\text { capaz de se } \\
\text { locomover? }\end{array}$ & - & $3,3 \%$ & $20 \%$ & $33,3 \%$ & $43,3 \%$ \\
\hline & $\begin{array}{l}\text { Quão satisfeita } \\
\text { você está com o } \\
\text { seu sono? }\end{array}$ & $3,3 \%$ & $26,7 \%$ & $36,7 \%$ & $23,3 \%$ & $10 \%$ \\
\hline & $\begin{array}{l}\text { Quão satisfeita } \\
\text { você está com sua } \\
\text { capacidade de } \\
\text { desempenhar as } \\
\text { atividades do seu } \\
\text { dia-a-dia? }\end{array}$ & $6,7 \%$ & $20 \%$ & $43,3 \%$ & $26,7 \%$ & $3,3 \%$ \\
\hline & $\begin{array}{c}\text { Quão satisfeita } \\
\text { você está com sua } \\
\text { capacidade para o } \\
\text { trabalho? }\end{array}$ & $10 \%$ & $20 \%$ & $33,3 \%$ & $36,7 \%$ & - \\
\hline \multirow[t]{5}{*}{ Psicológico } & $\begin{array}{c}\text { O quanto você } \\
\text { aproveita a vida? }\end{array}$ & - & $10 \%$ & $13,3 \%$ & $60 \%$ & $16,7 \%$ \\
\hline & $\begin{array}{l}\text { Em que medida } \\
\text { você acha que a } \\
\text { sua vida tem } \\
\text { sentido? }\end{array}$ & - & - & $16,7 \%$ & $50 \%$ & $33,3 \%$ \\
\hline & $\begin{array}{l}\text { O quanto você } \\
\text { consegue se } \\
\text { concentrar? }\end{array}$ & - & $10 \%$ & $46,7 \%$ & $43,3 \%$ & - \\
\hline & $\begin{array}{l}\text { Você é capaz de } \\
\text { aceitar sua } \\
\text { aparência física? }\end{array}$ & $3,3 \%$ & $10 \%$ & $26,7 \%$ & $50 \%$ & $10 \%$ \\
\hline & $\begin{array}{c}\text { Quão satisfeita } \\
\text { você está consigo } \\
\text { mesmo? }\end{array}$ & $3,3 \%$ & $13,3 \%$ & $13,3 \%$ & $60 \%$ & $10 \%$ \\
\hline
\end{tabular}


Tabela 3 - Qualidade de Vida das Gestantes.

\begin{tabular}{|c|c|c|c|c|c|c|}
\hline \multirow{2}{*}{\multicolumn{2}{|c|}{ Domínio }} & \multirow{3}{*}{$\begin{array}{c}\begin{array}{c}\text { Muito } \\
\text { insatisfeito }\end{array} \\
10 \%\end{array}$} & & & \multicolumn{2}{|c|}{ (Conclusão) } \\
\hline & & & \multirow{2}{*}{$\begin{array}{c}\text { Insatisfeito } \\
43,3 \%\end{array}$} & \multirow{2}{*}{$\begin{array}{c}\begin{array}{c}\text { Nem } \\
\text { Insatisfeito } \\
\text { Nem } \\
\text { Satisfeito }\end{array} \\
23,3 \%\end{array}$} & \multirow{2}{*}{$\begin{array}{c}\text { Satisfeito } \\
10 \%\end{array}$} & \multirow{2}{*}{$\begin{array}{c}\begin{array}{c}\text { Muito } \\
\text { Satisfeito }\end{array} \\
13,3 \%\end{array}$} \\
\hline & $\begin{array}{c}\text { Com que } \\
\text { frequência você } \\
\text { tem sentimentos } \\
\text { negativos como } \\
\text { mau humor, } \\
\text { ansiedade, } \\
\text { depressão? }\end{array}$ & & & & & \\
\hline \multirow[t]{3}{*}{ Pessoal } & $\begin{array}{l}\text { Quão satisfeita você } \\
\text { está com suas } \\
\text { relações pessoais? } \\
\text { Quão satisfeita você } \\
\text { está com sua vida }\end{array}$ & - & $16,7 \%$ & $10 \%$ & $60 \%$ & $13,3 \%$ \\
\hline & $\begin{array}{c}\text { sexual? } \\
\text { Quão satisfeita você } \\
\text { está com o apoio que } \\
\text { recebe de amigos? }\end{array}$ & $6,7 \%$ & $13,3 \%$ & $30 \%$ & $30 \%$ & $20 \%$ \\
\hline & & - & $6,7 \%$ & $13,3 \%$ & $50 \%$ & $30 \%$ \\
\hline \multirow[t]{8}{*}{ Profissional } & $\begin{array}{l}\text { Quão segura você } \\
\text { se sente em sua } \\
\text { vida diária? }\end{array}$ & $3,3 \%$ & $6,7 \%$ & $36,7 \%$ & $50 \%$ & $3,3 \%$ \\
\hline & $\begin{array}{l}\text { Quão saudável é o } \\
\text { seu ambiente } \\
\text { físico? } \\
\text { Você tem dinheiro } \\
\text { suficiente para }\end{array}$ & $3,3 \%$ & $6,7 \%$ & $43,3 \%$ & $20 \%$ & $26,7 \%$ \\
\hline & $\begin{array}{c}\text { satisfazer suas } \\
\text { necessidades? } \\
\text { Quão disponíveis } \\
\text { para você estão as }\end{array}$ & $3,3 \%$ & $10 \%$ & $43,3 \%$ & $30 \%$ & $13,3 \%$ \\
\hline & $\begin{array}{c}\text { informações que } \\
\text { precisa no seu dia- } \\
\text { a-dia? } \\
\text { Em que medida } \\
\text { você tem }\end{array}$ & - & $3,3 \%$ & $13,3 \%$ & $43,3 \%$ & $40 \%$ \\
\hline & $\begin{array}{l}\text { oportunidades de } \\
\text { atividade de lazer? } \\
\text { Quão satisfeita } \\
\text { você está com as }\end{array}$ & $3,3 \%$ & $20 \%$ & $26,7 \%$ & $40 \%$ & $10 \%$ \\
\hline & $\begin{array}{l}\text { condições do local } \\
\text { onde mora? } \\
\text { Quão satisfeita } \\
\text { você está com o }\end{array}$ & - & $3,3 \%$ & $6,7 \%$ & $46,7 \%$ & $43,3 \%$ \\
\hline & $\begin{array}{l}\text { seu acesso aos } \\
\text { serviços de saúde? } \\
\text { Quão satisfeita } \\
\text { você está com o }\end{array}$ & - & $6,7 \%$ & $10 \%$ & $33,3 \%$ & $50 \%$ \\
\hline & $\begin{array}{l}\text { seu meio de } \\
\text { transporte? }\end{array}$ & $3,3 \%$ & $10 \%$ & $13,3 \%$ & $33,3 \%$ & $40 \%$ \\
\hline
\end{tabular}

Fonte: Os autores (2020). 
A gestação e o puerpério são momentos em que as mulheres ficam ainda mais sensíveis, sendo capaz de terem inúmeros transtornos mentais. Segundo a OMS, as mulheres no geral, tem maior tendência de sofrimento mental comparado a população masculina (COSTA et al., 2018).

Ao analisar o contexto da pandemia do COVID-19, pesquisadores concluíram que o confinamento domiciliar trouxe muitas consequências psíquicas, como, o desenvolvimento de ansiedade, depressão, aumento do uso de psicotrópicos e diminuição do bem-estar intelectual das pessoas. Em relação as gestantes, públicoalvo da pesquisa, há um sofrimento mental duplicado ao observar que a mulher se encontra em um estado de profundas alterações hormonais e fisiológicas, além do medo diante ao vírus e o risco de morte neonatal ou materna (LÉLIS et al., 2020). É importante ressaltar que o público em questão necessita de uma atenção maior em todo período gestacional, incluindo o pré, durante e pós natal em meio à pandemia do COVID-19 (ESTRELA et al., 2020).

\section{CONCLUSÃO}

Ao analisar os resultados dos dados utilizando o instrumento WHOQOL-bref nestas participantes da pesquisa, observou-se que a maioria das gestantes entrevistadas $(93,3 \%)$ apresentou uma boa qualidade de vida no período da pandemia. A maior parte relatou ter modificado de forma positiva sua alimentação e metade delas alegam praticar exercícios físicos, dentre outros cuidados importantes para a mulher e para seu concepto, no entanto, sugere-se que novos estudos com amostras maiores, sejam realizados com este público para garantir uma gestação saudável.

\section{AGRADECIMENTOS}

As autoras agradecem a Instituição Presbiteriana Mackenzie e a professora Márcia Nacif por todo apoio e colaboração na elaboração do presente estudo.

\section{REFERÊNCIAS}

ALMEIDA, M. O.; PORTUGAL, T. M.; ASSIS, T. J. C. F. Gestantes e COVID-19: Isolamento Como Fator de Impacto Físico e Psíquico. Revista Brasileira de Saúde Materno infantil, Recife, v. 20, n. 2, p. 603-606, 2020. Doi: 10.1590/180693042020000200015

AMERICAN COLLEGE OF SPORTS OF MEDICINE. (ACSM). Staying active during the coronavirus pandemic. 2020. Disponível em: https://www.exerciseismedicine.org/assets/page documents/EIM Rx\%20for\%20Heal th \%20Staying\%20Active\%20During\%20Coronavirus\%20Pandemic.pdf. Acesso em: 18 dez. 2020.

BENVENUTO, D. et al. The 2019-new coronavirus epidemic: evidence for virus evolution. Journal of Medical Virology, v. 92, n. 4, p. 455-459, 2020. Doi: 10.1002/jmv.25688 
BRASIL. ORGANIZAÇÃO PAN-AMERICANA DE SAÚDE. Folha informativa

COVID-19: Escritório da OPAS e da OMS no Brasil. Atualizado em 17 de dezembro 2020. Disponível em: https://www.paho.org/pt/covid19\#risco. Acesso em: 18 dez. 2020a.

BRASIL. Decreto $n^{\circ} 10.211$, de 30 de janeiro de 2020. Dispõe sobre o Grupo Executivo Interministerial de Emergência em Saúde Pública de Importância Nacional e Internacional - GEI-ESPII. Diário Oficial da União, Brasília, 30 jan. 2020b, Ed.21A, Seção. 1 Extra, p.1. Disponível em: https://www.in.gov.br/en/web/dou/-/portaria-n188-de-3-de-fevereiro-de-2020-241408388. Acesso em: 15 out. 2020.

BVS. Qualidade de Vida em 5 Passos: uma meta ao seu alcance. Brasília:

Secretaria de Saúde do Distrito Federal, 2013. Disponível em:

https://bvsms.saude.gov.br/bvs/dicas/260 qualidade de vida.html. Acesso em: 18 dez. 2020.

COSTA, D. O. et al. Transtornos mentais na gravidez e condições do recém-nascido: estudo longitudinal com gestantes assistidas na atenção básica. Revista Ciência \& Saúde coletiva, v. 23, n. 3, p. 691-700, 2018.

CRUZ, M. V.; FRANÇA, S. Q. N.; GRUBER, C. Informação e Qualidade De Vida no Período Gestacional. Cadernos da Escola de Saúde, v. 1, n.5, p.14-22, 2011.

ESTRELA, F. M. et al. Gestantes no contexto da pandemia da COVID-19: reflexões e desafios. Physis, v. 30, n. 2, p. 1-5, 2020. Doi: 10.1590/S0103-73312020300215

GADELHA, I. P. et al. Qualidade de vida de mulheres com gravidez de alto risco durante o cuidado pré-natal. Revista Brasileira de Enfermagem, v. 73, n. supl. 5, p.1-7, 2020. Doi: 10.1590/0034-7167-2019-0595

GUEDES, B. L. C. S. et al. Aspectos gerais da COVID-19 na saúde de gestantes e recém-nascidos: Uma breve revisão. Research, Society and Development, v. 9, n. 7, p. 1-16, 2020. Doi: 10.33448/rsd-v9i7.4969

HOFFMANN, M. et al. SARS-CoV-2 cell entry depends on ace 2 and tmprss 2 and is blocked by a clinically proven protease inhibitor. Cell, v. 181, n. 2, p. 271-280, 2020. Doi: 10.1016/J.CELL.2020.02.052

LÉLIS, B. D. B. et al. O Sofrimento Mental das Gestantes em Meio a Pandemia do Novo Coronavírus no Brasil. ID on line: Revista de Psicologia, v. 14, n. 52, p. 442451, 2020. Doi: 10.14295/idonline.v14i52.2676 
MIORANDO, N.; MACIEL, C. L. Z. Avaliação dos sintomas comuns e do uso de suplementação durante a gestação, em puérperas internadas em um hospital privado na cidade de Cascavel - Paraná. Fag Journal Of Health, n esp, p. 54-55, 2019. DOI: 10.35984/FJH.V0I0.37

OLIVEIRA, M. H. M. Perfil epidemiológico e hábitos alimentares de gestantes de alto risco acompanhadas em centro de referência do município de Vitória de Santo Antão - PE. 2019. 64p. Trabalho de conclusão de Curso (Graduação em Nutrição) Universidade Federal de Pernambuco, Vitória de Santo Antão, 2019.

REIS JÚNIOR, D. R. Qualidade de Vida no Trabalho: construção e validação do questionário QWLQ-78. 2008. 114p. Dissertação (Mestrado em Engenharia de Produção), Universidade Tecnológica Federal do Paraná, Ponta Grossa, 2008. Disponível em:

http://www.pg.utfpr.edu.br/ppgep/dissertacoes/arquivos/101/Dissertacao.pdf. Acesso em: 23 out. 2020.

SANTANA, E. F. M.; ELITO JÚNIOR, J. Gestação múltipla no surto de SARS-CoV-2: o desafio do pré-natal. Einstein, v. 18, p. 1-2, 2020. Doi: 10.31744/einstein_journal/2020CE5990

TANG, N. et al. Anticoagulant treatment is associated with decreased mortality in severe coronavirus disease 2019 patients with coagulopathy. Journal of thrombosis and haemostasis, v. 18, n. 5, p. 1094-1099, 2020. Doi: 10.1111/jth.14817

THE WHOQOL GROUP. Development of the world health organization Whoqol-Bref quality of life assessment. Psychological Medicine, v.28, n.3, p. 551-558, 1998. Doi: $10.1017 /$ S0033291798006667.

WAGNER, A. et al. Vulnerabilidades para gestantes e puérperas durante a pandemia da covid-19 no estado de Santa Catarina, Brasil. Hygeia: Revista Brasileira de Geografia Médica e da Saúde, n. esp, p. 398-406, 2020. Doi: https://doi.org/10.14393/Hygeia0054630

WEFFORT, V. R. S. et al. Transmissão vertical da COVID-19: uma revisão integrativa. Residencia Pediátrica, v. 10, n. 2, p. 1-5, 2020. Doi:

10.25060/residpediatr-2020.v10n2-343 